\author{
МАРИНА МитюковА
}

\title{
Некоторые вопросы ограничения права собственности при расследовании преступлений
}

По мере становления и развития права, именно право и свойственные ему методы защиты стали с провозглашением святости, неприкосновенности собственности приоритетными элементами основы существования и развития права собственности. Защита права собственности в контексте ее неприкосновенности, святости ныне является одним из основных элементов статуса собственника.

1. Важнейшим объектом собственности выступает жилище. Статья 25 Конституции Российской Федерации от $12.12 .1993^{1}$ предусматривает:

Жилище неприкосновенно. Никто не вправе проникать в жилище против воли проживающих в нем лиц иначе как в случаях, установленных федеральным законом, или на основании судебного решения.

Право на неприкосновенность жилища означает, что никто не может без законного основания войти в жилище против воли проживающих в нем лиц. Каждый человек имеет право на свой образ жизни, обособление, уединение в занимаемом им и его близкими помещении. Из положений ст. 12 Всеобщей декларации прав человека (принята Генеральной Ассамблеей ООН 10.12.1948)² и ст. 17 Международного Пакта от 16.12.1966 О гражданских и политических правах ${ }^{3}$, ст. 8 Конвенции о защите прав человека и основных свобод (заключена в г. Риме 04.11.1950)4, а также ст. 25 Конституции РФ следует, что никто не может подвергаться произвольным или незаконным посягательствам на неприкосновенность его жилища.

1 С3 РФ - Собрание законодательства Российской Федерации. 2009 № 4, Ст. 445.

2 Рос. газета. 1998-12-10.

3 БВС РФ - Бюллетень Верховного Суда Российской Федерации. 1994 № 12.

4 С3 РФ. 2001 № 2, Ст. 163. 
52 | Adam Mickiewicz University Law Review

Уголовное судопроизводство является сферой широкого и интенсивного применения мер государственного принуждения, без которого во многих случаях невозможно эффективное осуществление производства по уголовному делу. Вследствие этого, закрепленное в ст. 25 Конституции РФ право на неприкосновенность жилища также может быть ограничено в ходе уголовного судопроизводства. Однако обязательным условием правомерности ограничения данного права в уголовном судопроизводстве является наличие на то достаточных фактических и процессуальных оснований.

Официальная статистика свидетельствует, что доля преступлений, совершаемых в жилище, весьма значительна. Так, по данным МВД РФ - Министерство внутренних дел Российской Федерации, 42,5\% зарегистрированных преступлений составляют хищения чужого имущества. Почти каждая третья кража $(32,3 \%)$, каждое одиннадцатое разбойное нападение $(8,8 \%)$ и каждый двадцать четвертый грабеж $(4,2 \%)$ были совершены в жилище. В связи с этим в процессе расследования преступлений достаточно часто возникает необходимость производства следственных действий в жилище.

Уголовно-процессуальное право устанавливает перечень субъектов применения норм о законных отступлениях от конституционного принципа неприкосновенности жилища (и соответственно ограничения прав собственника жилища) и следственных действиях, при осуществлении которых возникает необходимость использования указанного права. В соответствии со ст. 29 Уголовно-процессуального кодекса РФ от 18.12.2001 (далее по тексту - УПК РФ) дятся в жилище на основании судебного решения: осмотр жилища при отсутствии согласия проживающих в нем лиц (ч. 5 ст. 177 УПК РФ), обыск и выемка в жилище (ч. 3 ст. 182 , ч. 2 ст. 183 УПК РФ).

2. Осмотр жилища - следственное действие, производимое в целях обнаружения следов преступления и иных уголовно-релевантных следов, других предметов, документов и веществ, выяснения обстановки происшествия, а равно иных обстоятельств, имеющих значение для уголовного судопроизводства. В уголовно-процессуальном законодательстве используется широкое понятие термина жилище, что обеспечивает неприкосновенность жилища не только его собственника, но и лиц, проживающих в нем на других законных основаниях.

УПК РФ в п. 10 ст. 5 дал следующее определение жилища:

Жилище - индивидуальный жилой дом с входящими в него жилыми и нежилыми помещениями, жилое помещение независимо от формы собственности, входящее в жилищный фонд и используемое для постоянного или временного проживания, а равно иное помещение или строение, не входящее в жилищный фонд, но используемое для временного проживания.

5 СЗ РФ. 2001 № 52 (ч. І), Ст. 4921. 
Как справедливо замечают некоторые авторы, из данного определения следует, что теперь любое помещение, не входящее в жилищный фонд и не предназначенное для жилья (например, гараж, подвал и т.п.), но используемое лицами без определенного места жительства для временного проживания, УПК РФ признает жильем, и в соответствии со ст. 12, ч. 2 ст. 164 УПК РФ невозможно произвести там осмотр без согласия всех проживающих в нем лиц или на основании предварительно полученного судебного решения.

Следует отметить, что существует и другое законодательное определение понятия жилище, данное в примечании к ст. 139 Уголовного кодекса РФ от 13.06.1996 (далее по тексту - УК РФ) ${ }^{6}$ :

Жилище - индивидуальный жилой дом с входящими в него жилыми и нежилыми помещениями, жилое помещение независимо от формы собственности, входящее в жилищный фонд и пригодное для постоянного или временного проживания, а равно иное помещение или строение, не входящее в жилищный фонд, но предназначенное для временного проживания.

Представляется, что определение жилища, данное в УК РФ, является более удачным и с ним должно быть приведено в соответствие процессуальное определение рассматриваемого понятия.

Осмотр жилища производится только с согласия проживающих в нем лиц или на основании судебного решения. Если проживающие в жилище лица возражают против осмотра, то следователь с согласия руководителя следственного органа, а дознаватель с согласия прокурора возбуждают ходатайство перед судом о производстве такого осмотра (ч.5 ст.177 УПК РФ). Таким образом, судебное решение является важнейшей гарантией законного ограничения права собственника и иных, проживающих на законных основаниях лиц на неприкосновенность жилища.

Немало вопросов у практических работников вызывает формулировка о необходимости получения согласия на осмотр жилища проживающих в нем лиц. Законодатель не раскрывает сущности данного понятия. Поэтому многие комментаторы Конституции РФ отмечают, что только лица, наделенные правом владения и пользования, а также правом собственности на занимаемое жилое помещение, будь то место жительства или место пребывания, что подтверждается правоустанавливающими документами (договор аренды, найма, субаренды, поднайма, свидетельство о праве собственности и т.п.), обладают основным правом на неприкосновенность жилища.

Вместе с тем неясно, как должен поступить следователь, если лица постоянно или временно проживающие в жилище отсутствуют? Действия следователя в подобных

6 СЗ РФ. 1996 № 25, Ст. 2954. 
54 | Adam Mickiewicz University Law Review

ситуациях закон не регламентирует. Невозможно же доставить этих лиц приводом. Закон не запрещает производство осмотра жилища в отсутствие проживающих в нем лиц. Но каким образом следователь может попасть в жилище? При этом в законе не содержится требование приглашения посторонних граждан (кроме понятых). В литературе высказана точка зрения, что:

при наличии оснований для производства осмотра места происшествия в жилище, допускается принудительное вхождение в жилище, в том числе с применением физической силы и вскрытием закрытых дверей. В таких случаях необходимо пригласить представителей жилищно-эксплуатационной организации. Вскрытие иных хранилищ в осматриваемом жилище в рамках процедуры осмотра не допускается .

А если осматриваемое жилище находится в собственности? Как следователю осуществлять принудительное вхождение в жилище, если собственники жилья отсутствуют, и никто не присматривает за домом (например, это дачный дом в сельской местности, а собственник постоянно проживает в отдаленном месте?). Поскольку вопрос законодателем не урегулирован, представляется, что в подобных ситуациях для участия в следственном действии необходимо пригласить представителей органов местного самоуправления, что будет выступать дополнительной гарантией соблюдения прав собственника жилища.

Следует отметить, что в УПК РФ не указано, каким образом необходимо оформлять согласие на осмотр жилища лиц, проживающих в нем. Понятно, что согласие собственника (иного проживающего лица) должно быть письменно зафиксировано перед началом осмотра. Поэтому существует мнение, которое поддерживает часть опрошенных следователей о том, что такое согласие должно фиксироваться в протоколе данного следственного действия. Другая часть опрошенных следователей полученное согласие на осмотр жилища оформляют отдельным заявлением и удостоверяют своей подписью и подписями приглашенных понятых.

При применении данной нормы может возникнуть ситуация, когда жилище принадлежит в долях разным собственникам, и кто-то один выражает несогласие с производством осмотра или отсутствует дома и не может письменно выразить свое мнение. При таких обстоятельствах принципу неприкосновенности жилища соответствует требование о необходимости получения судебного решения, за исключением случаев, не терпящих отлагательства.

Возможна другая ситуация, когда собственник (или лицо, проживающее в жилище на других законных основаниях) дал согласие на производство осмотра, но во время

7 Е.Ю. Алонцева, Полномочия следователя по производству следственных действий, выполняемых с разрешения суда, Москва 2008, С. 89. 
осмотра заявил о своем несогласии с дальнейшим производством и окончанием осмотра. Как справедливо замечает Н. Лопаткина, в данном случае дальнейшее производство осмотра будет являться нарушением конституционных прав собственника на неприкосновенность жилища, поэтому следует обратиться в суд за соответствующим решением, если ситуация не относится к случаям не терпящим отлагательства ${ }^{8}$.

На практике нередко возникает необходимость проведения осмотра места происшествия в жилище. В данной ситуации у следователей возникает ряд вопросов: следует ли получать судебное решение на осмотр места происшествия в жилище в случае отсутствия согласия проживающих в нем лиц, либо руководствоваться нормами, регламентирующими общий порядок осмотра места происшествия? Как быть, если, например, убийство либо причинение тяжкого вреда здоровью произошло в квартире, собственник которой, по сути, является основным подозреваемым и, конечно же, возражает против вторжения в жилище и производства следственных действий? Можно ли производить осмотр жилища, являющегося местом происшествия, до возбуждения уголовного дела? УПК РФ ответ на данные вопросы не дает. Опрос следователей показал, что применительно к данной ситуации в разных регионах, учитывая конкретные обстоятельства, поступают по-разному. В одних регионах следователи до начала осмотра места происшествия в жилище возбуждают перед судом ходатайство о даче разрешения на осмотр. В других регионах - на месте выносят постановление об осмотре жилища без согласия проживающих в нем лиц, мотивируя осмотр как исключительный случай, не терпящий отлагательства. В третьих - производят осмотр жилища по правилам осмотра места происшествия. Во всех случаях протоколы таких осмотров места происшествия или жилища не были признаны недопустимыми доказательствами по данному основанию.

Полагаем, что в целях единообразного понимания и применения закона на всей территории России, а также в целях надлежащей защиты прав собственника жилья по данному вопросу в УПК РФ следует внести дополнения. Причем на страницах юридических изданий законодателю предлагаются различные варианты решения рассматриваемой проблемы. Первый вариант - дать законодательное определение места происшествия, указав в нем и жилище. Например,

место происшествия - это участок местности, помещение или жилище, где обнаружены признаки либо следы преступления, иные уголовно-релевантные следы, а равно другие обстоятельства, свидетельствующие о совершении преступления9.

8 Н. Лопаткина, Реализация принципа неприкосновенности жилища в уголовном судопроизводстве, Рос. юстиция 11/ 2002, С. 51.

9 Е.М. Варпаховская, Производство следственных действий в российском уголовном судопроизводстве: правовое регулирование и вопросы применения, Иркутск 2006, С. 39. 
56 | Adam Mickiewicz University Law Review

В данном случае не будет необходимости решать вопрос о получении согласия лиц, проживающих в данном жилище, которые могут являться и лицами, совершившими преступления. Некоторые авторы настаивают на том, что осмотр места происшествия в жилище нельзя ставить в зависимость от волеизъявления лица (в том числе и собственника жилища), совершившего преступление в жилище ${ }^{10}$. Такой вариант решения проблемы желательным считают большинство опрошенных следователей. Близким по способу решения является предложение некоторых авторов о внесении изменений в ч. 5 ст. 177 УПК РФ и изложения ее в следующей редакции: Осмотр жилища (за исключением места происшествия) производить только с согласия проживающих в нем лии или на основании судебного решения (... $)^{11}$.

Среди опрошенных практических работников имеет место и такой вариант решения рассматриваемой проблемы. Учитывая, что неприкосновенность жилища гарантирована нормами международного права, Конституцией РФ, она должна соблюдаться и субъектами уголовного преследования. Поэтому следует сохранить правила осмотра жилища, в том числе и при осмотре в нем места происшествия. Однако при этом в ч. 5 ст. 177 УПК РФ следует внести изменение о том, что если проживающие в жилище лица возражают против осмотра, то следователь возбуждает перед судом ходатайство о производстве осмотра в соответствии со ст. 165 УПК РФ, в том числе до возбуждения уголовного дела. Возможно такое решение проблемы позволит следователю на законном основании провести данное следственное действие, не нарушив прав лиц, проживающих в жилище. Однако, как быть в случаях, не терпящих отлагательства? До тех пор, пока в УПК РФ не будут внесены изменения, касающиеся уточнения осмотра места происшествия в жилище, полагаем, что при осмотре места происшествия в жилище в соответствии с принципом неприкосновенности жилища, следует испрашивать согласие проживающих и находящихся в необходимый момент в жилище лиц. В случае отказа в даче такого согласия, но необходимости производства осмотра в связи с его неотложностью, следует руководствоваться требованиями ч. 5 ст. 165 УПК РФ. Для этого, первоначально, на месте происшествия решить вопрос о возбуждении уголовного дела, далее вынести постановление о необходимости осмотра жилища без судебного решения и произвести соответствующий осмотр, уведомив судью и прокурора. Когда уголовное дело возбуждено, перед началом осмотра следователь предъявляет соответствующее постановление суда. При вхождении в жилище следователь объявляет присутствующим, какое следственное действие будет производиться, и в чем состоит его цель.

10 В.Н. Исаенко, Обеспечение допустимости доказательств, полученных в результате проведения следственных действий, Москва 2004, С. 21.

11 В. Белоусов, Осмотр места происшествия в жилище и осмотр жилища, Уголовное право 3/2005, C. 72 . 
В исключительных случаях, не терпящих отлагательства, осмотр жилища может быть произведен на основании постановления следователя без получения судебного решения (ч. 5 ст. 165 УПК РФ). В этом случае, в течение 24 часов следователь уведомляет об этом прокурора и судью в письменной форме. К уведомлению прилагаются копия постановления и копия протокола осмотра жилища для проверки законности решения. В срок не позднее 24 часов с момента получения уведомления судья в судебном заседании устанавливает наличие или отсутствие юридических и фактических оснований для производства следственного действия, ограничивающего конституционные права и свободы личности, и проверяет законность произведенного следственного действия. На наш взгляд, в ст. 165 УПК РФ необходимо внести дополнение, касающееся обязательного участия следователя в данном судебном заседании. В судебном заседании должны быть выслушаны доводы следователя, подтверждающие исключительность случая и причины, по которым не представилось возможным получить разрешение суда. В случае если судья признает проведение осмотра незаконным, все доказательства, полученные в ходе его производства, признаются недопустимыми и не могут быть положены в основу обвинения (ч. 5 ст. 165 УПК РФ). В данном судебном заседании вправе принимать участие защитник обвиняемого (подозреваемого) и лицо, неприкосновенность жилища которого была ограничена.

3. Обыск представляет собой следственное действие, направленное на отыскание и изъятие орудий преступления, предметов, документов, и ценностей, которые могут иметь значение для уголовного дела, для обнаружения разыскиваемых лиц и трупов (ч. 1 ст. 182 УПК РФ). Характерными чертами обыска являются его поисковый характер и принудительность. Поскольку обыск существенно ограничивает права собственника на неприкосновенность жилища, сопровождается, как правило, изъятием различных объектов. В жилище он может быть проведен только на основании судебного решения, за исключением случаев, не терпящих отлагательства, при которых судебный контроль законности действий следователя действует после их совершения. При принятии решения о производстве обыска в жилище судья должен тщательно изучить фактические основания его производства, которые могут быть установлены как имеющимися доказательствами в уголовном деле, так и данными оперативно-розыскного характера.

Перед началом обыска следователь предъявляет решение суда, разрешающее его производство, а в случаях, не терпящих отлагательства, следователь производит следственное действие на основании своего постановления. К ситуациям, не терпящим отлагательства, например, относятся случаи, когда фактические основания к производству обыска появились внезапно, при производстве других следственных действий; поступили сведения о том, что лицо, владеющее имеющими значение для уголовного дела объектами, принимает меры к их уничтожению или сокрытию; обыск необходим 
58 | Adam Mickiewicz University Law Review

для пресечения дальнейшей преступной деятельности; обнаружения и задержания преступника и др.

Обыск проводится у обвиняемых и подозреваемых, но закон не запрещает проводить обыск и у иных лиц, если имеются основания полагать, что у них могут находиться орудия преступления, предметы, документы и ценности, имеющие значение для дела (ч. 1 ст. 182 УПК РФ). Важной гарантией соблюдения прав собственника выступает положение закона о присутствии лица, у которого производится обыск, либо совершеннолетних членов его семьи. Буквальное толкование ч. 11 ст. 182 УПК РФ говорит о том, что в отсутствие проживающих в жилище лиц вхождение в него с целью обыска недопустимо. Однако многие авторы утверждают, что:

данная норма неэффективна, поскольку фактически ставит производство обыска в зависимость от лиц, не заинтересованных в его проведении. Доставление их для целей производства обыска выходит за рамки закона ${ }^{12}$.

В то же время права собственников жилья существенно ограничиваются - анализ практики показывает, что зачастую, если собственник жилья задержан по подозрению в совершении преступления, и возникла необходимость производства обыска, следователи не доставляют подозреваемых, а предпочитают проводить обыск в их отсутствие, хотя подозреваемый находится в органах внутренних дел. Указанное нарушение закона в достаточно редких случаях влечет признание обыска и его результатов незаконными.

Так, Президиум Верховного Суда РФ отменил приговор и кассационное определение в отношении П., обвиняемого по ч. 1 ст. 222 УК РФ - Уголовный кодекс Российской Федерации, и прекратил производство по уголовному делу за отсутствием в действиях состава преступления в связи с тем, что при обыске не было обеспечено присутствие лица, у которого производился обыск либо совершеннолетних членов его семьи. Из протокола обыска усматривалось, что он был начат в доме П., но проводился в его отсутствие, П. в это время находился в помещении органа внутренних дел, был задержан. При таких обстоятельствах органы предварительного следствия имели реальную возможность обеспечить участие П. в проведении данного следственного действия, однако не сделали этого ${ }^{13}$.

Как быть в ситуациях, когда подозреваемый, обвиняемый проживает один и заключен под стражу по решению суда? Вряд ли его доставят для участия в обыске. Но, во-первых, его право на добровольную выдачу имущества, имеющего значение для уголовного дела, может быть реализовано в ходе допроса - он может назвать места хранения данного имущества. Во-вторых, УПК РСФСР - Уголовно-процессуальный

12 Е.Ю. Алонцева, Полномочия следователя, С. 94.

13 Определение № 48-Дп 02-14 по делу Довжика, Научно-практич. пособие по применению УПК РФ, Москва 2004, С. 360-361. 
кодекс Российской Советской Федеративной Социалистической Республики ${ }^{14}$ содержал правило (ч. 2 ст. 169) о том, что при отсутствии лица, в жилище которого производится обыск и совершеннолетних членов его семьи, органы расследования обязаны были привлекать представителей жилищно-эксплуатационной организации, исполнительного комитета поселкового или Сельского Совета народных депутатов. Полагаем, что в целях обеспечения прав как обвиняемых (подозреваемых), так и потерпевших УПК РФ следует дополнить аналогичным правилом.

Важной гарантией соблюдения прав собственника имущества при производстве обыска является положение закона о том, что следователь до начала обыска обязан предложить добровольно выдать подлежащие изъятию предметы, документы, ценности, которые могут иметь значение для уголовного дела (ч. 5 ст. 182 УПК РФ). Добровольная выдача всех предметов, имеющих отношение к уголовному делу, означает, что следователь вправе не производить поисковых действий (никто не ходит по жилищу, не вскрывает запертое, не изымает другие вещи и т.п.), что и должно найти отражение в протоколе. При производстве обыска во всех случаях следователь изымает предметы и документы, изъятые из гражданского оборота.

Постановление судьи о разрешении производства обыска в жилище или постановление следователя о производстве обыска в ином помещении наделяет следователя полномочиями беспрепятственно входить в подлежащие обследованию помещения, в том числе принудительно вскрывать как в целом помещение, так и любые хранилища и объекты, находящиеся внутри обыскиваемых помещений. Однако принудительное вскрытие помещений допускается, если владелец отказывается их открыть добровольно. При этом закон запрещает повреждать имущество, если это не вызывалось необходимостью. Надо признать, что данная формулировка закона довольно расплывчата, поскольку любые действия следователя по повреждению имущества, связанные с розыском орудий преступления, предметов, документов и ценностей, которые могут иметь значение для уголовного дела, всегда будут считаться, как вызванные необходимостью. Речь, скорее всего, должна идти о явно незаконных действиях следователя при производстве обыска. Например, вместо того, чтобы распороть обшивку дивана или кресел по шву ее скрепления с каркасом, она режется ножом в самых видных местах или вместо того, чтобы прощупать обои, они срываются со стены с целью обнаружения тайника и т. д. Поэтому, если лицо, в помещении которого производился обыск, и его защитник посчитают, что в результате обыска произошло повреждение имущества, которое не вызывалось необходимостью, и особенно в тех случаях, когда обыск дал отрицательный результат, необходимо все повреждения имущества отразить в протоколе обыска с точным описанием всех действий следователя, а затем предъявить исковые требования к государству по возмещению вреда, причиненного

14 Ведомости ВС РСФСР. 1960 № 40, Ст. 592. 
60 | Adam Mickiewicz University Law Review

в результате проведенного обыска. Именно по протоколу можно проверить весь ход следственного действия. Поэтому все, что не указал следователь в отношении порчи имущества, обязана сделать сторона защиты в замечаниях и дополнениях к протоколу обыска.

Производство обыска обеспечивается государственным принуждением, в связи с чем следователь вправе запретить лицам, присутствующим в месте, где производится обыск, покидать его, а также общаться друг с другом или иными лицами до окончания обыска.

При производстве осмотра, обыска и выемки в жилище следователь обязательно обеспечивает участие двух понятых. Кроме того, для участия в следственном действии допускается и большее число понятых в тех случаях, когда поисковые действия осуществляют несколько следователей и сотрудников органов дознания в разных местах. Изъятые при обыске предметы, документы, ценности предъявляются понятым и другим лицам, присутствующим при обыске, и в случае необходимости упаковываются и опечатываются на месте обыска, что удостоверяется подписями следователя и понятых. Данные действия по оформлению документов и вещественных доказательств имеют важное значение, как для обеспечения прав потерпевшего лица, так и для возвращения изъятого при установлении невиновности обвиняемого (подозреваемого). При производстве обыска следователь составляет протокол, в котором должны быть указаны все изъятые объекты. Копия протокола вручается лицу, в жилище которого был произведен обыск, либо совершеннолетнему члену его семьи.

4. Процессуальный порядок выемки в жилище тот же, что и для обыска, но с некоторыми исключениями, которые обусловлены тем, что, в отличие от обыска, предметы и документы, подлежащие изъятию, не разыскиваются, а лишь изымаются добровольно или принудительно. До начала выемки следователь объявляет постановление суда и предлагает выдать предметы и документы, подлежащие изъятию, а в случае отказа производит выемку принудительно. Выемка производится, когда заранее известно место нахождения искомого предмета. Вместе с тем производство выемки обеспечивается принуждением государства, позволяющим свободно входить в жилище и при необходимости вскрывать запертые хранилища, в которых размещены подлежащие изъятию объекты. Однако такое принуждение ограничивается целями выемки - оно должно обеспечить доступ строго к определенному предмету.

В случаях, когда в ходе выемки объект, подлежащий изъятию, в точно указанном месте не обнаружен, но имеются основания полагать, что он хранится в этом же жилище, следователю необходимо составить протокол выемки, в котором указать, что предмет не обнаружен и не изъят. Затем провести обыск в жилище по правилам случаев, не терпящих отлагательства (ч. 5 ст. 165 УПК РФ).

Таким образом, производство следственных действий достаточно часто связано с ограничением священного права собственности физических и юридических лиц, что 
вызвано необходимостью расследования преступлений и установления лиц его совершивших. Органы предварительного расследования обязаны соблюдать установленный федеральным законом механизм законного ограничения права собственности, важнейшей составляющей которого является получение судебного решения на производство следственных действий.

\section{Биографическая аннотация:}

Марина Митюкова - Иркутский государственный университет, Юридический институт, преподаватель кафедры судебного права. Научные интересы: уголовно-процессуальное право, защита прав человека.

\section{SUMMARY}

\section{Selected issues of the property right limitation in the criminal proceedings}

The study aims at an analysis of the relationship between civil law and the criminal procedure law system. The author focus on the limitation of the property right in the selected aspects of the criminal proceedings.

KEYWORDS: limitation the property right, criminal proceedings, civil law 
